\title{
O sono louco
}

Daniel Jablonski*

RESUMO: O sono louco é o título de trabalho de um projeto exibido recentemente como instalação na galeria Casamata, no Rio de Janeiro. Combinando métodos de pesquisa acadêmica com prática artística, o projeto investiga os problemas de sono do próprio artista, por meio de um teste caseiro realizado no período de um mês com um relógio de ponto de vigia noturno do século XIX. Os resultado obtidos pareceram apontar para a existência de um transtorno psíquico transitivo que consiste em uma notável resistência em despertar-se, um problema ainda pouco estudado na passagem entre sono e vigília. O presente ensaio apresenta uma tentativa de interpretar esse "estudo de caso" em primeira pessoa, com referências à ciência dos sonhos de Freud, às estruturas de dominação do capitalismo industrial e ao amor louco dos surrealistas.

PALAVRAS-CHAVE: sono, inconsciente, máquina

ABSTRACT: The Mad Sleep is the working title for a project recently exhibited as an installation piece at Casamata gallery, in Rio de Janeiro. Combining research methods with art practice, the project investigates the artist's own sleeping problems, by means of a month-long test conducted at his home using a $19^{\text {th }}$ century night watchman's clock. The results obtained seem to point to the existence of a psychic transitional disorder consisting in a marked resistance to waking up, a

\footnotetext{
*Daniel Jablonski é artista plástico e pesquisador independente. Sua produção recente apoia-se em pesquisa em andamento acerca da emergência do discurso mitológico na primeira metade do século XX (literatura, antropologia, psicanálise) e sua ligação com o advento e a popularização do aparelho fotográfico. E-mail: danieljablonski@vousvoici.com
} 
little studied problem in the passage between sleep and vigil. This essay presents the attempt to interpret this 'case study' in the first person, with references to Freud's science of dreams, the domination structures of industrial capitalism and the Surrealist's mad love.

KEYWORDS: sleep, unconscious, machine

C'est fini le temps des poètes. Aujourd'hui je dors. - Gil J. Wolman

Em conclusão a um conhecido fragmento intitulado Madame Ariane, segundo pátio à esquerda, Walter Benjamin escreve em Rua de mão única: "O dia jaz cada manhã como uma camisa fresca sobre nossa cama; esse tecido incomparavelmente fino, incomparavelmente denso, de limpa profecia, assenta-nos como uma luva. A felicidade das próximas vinte e quatro horas depende de que nós, ao acordar, saibamos como apanhá-lo". (BENJAMIN, 1995, p. 64) "Ao acordar", diz ele, e isso não é um detalhe menor. Pelo contrário: ao lermos suas notas preparatórias para Les Passages parisiens, feitas entre 1927 e 1929, damo-nos conta de que o ato do despertar é quase uma obsessão para o autor. A expressão aparece incontáveis vezes ao longo daquelas linhas e não é empregada apenas no sentido de um simples indivíduo dormindo. Ela é apresentada, muito mais além, como um "novo método dialético" para a "ciência histórica" ela mesma, cuja estratégia é resumida assim: "experienciar o presente como o mundo da vigília ao qual se refere o sonho que chamamos de o ocorrido. Elaborar o ocorrido na recordação do sonho!" (BENJAMIN, 2007, p. 434) Aplicando as ferramentas analíticas de Sigmund Freud ao exame da cultura material de uma época, Benjamin pretendia estender a esfera privada (e burguesa) do sonho a uma dimensão radicalmente coletiva e histórica - elevando, com o mesmo gesto, a ação cotidiana do despertar a uma dignidade política inédita. Afinal, como ele sugere ainda, "a experiência da juventude de uma geração tem muito em comum com a experiência do sonho. Sua configuração histórica é configuração onírica. Cada 
época tem um lado voltado para os sonhos, o lado infantil. Para o século passado, isto aparece claramente nas passagens". (BENJAMIN, 2007, p. 433) Despertar-se em meados dos anos 1930 significava então despertar todo o século XIX, retornando a esse mundo infantil e onírico da passagens parisienses, a fim de trazer alguma luz ao conhecimento "inconsciente" do passado que elas abrigavam. Tratava-se, enfim, de compreender o que antes havia sido apenas vivido. Mas, contrariamente à teoria freudiana, o modelo para esse novo sujeito do despertar — guiando a cultura da infância à fase adulta - não era o analista em um consultório, senão o historiador nos arquivos.

\section{1.}

Nunca quis ser historiador, mas gosto bastante de História e alguns de meus interesses teóricos cruzam frequentemente o século XIX. Assim como Benjamin, também gosto de passar a maior parte do meu tempo na biblioteca, lendo velhos livros, tomando notas, indo a arquivos etc. Mas acima de tudo, assim como Benjamin, também gosto de acordar cedo. Contudo isso nunca ocorre. Toda manhã, fins de semana e feriados inclusos, eu luto com meu despertador. Desde a adolescência — quando meus pais deixaram de me acordar — eu ajusto o alarme de bom grado todas as noites e durmo com muita facilidade. Na manhã seguinte, entretanto, sou perfeitamente incapaz de determinar o que aconteceu. O alarme tocou? Ou eu o desliguei? Se foi esse o caso, quando? Não é fácil de dizer, já que não há nenhum padrão claro entre a hora estipulada do alarme e a hora em que de fato acordo. Às vezes isso me toma alguns minutos, às vezes algumas horas. A única coisa segura a se dizer é que a dor física está sempre envolvida. Sem mencionar, é claro, a culpa que segue naturalmente cada despertar tardio, após ter sido chamado por anos a fio de preguiçoso, indolente etc. Isso logo toma a forma de um círculo vicioso: quanto mais se tenta acordar cedo, mais frustração acompanha cada nova derrota. Nesse sentido, quer se acredite ou não que o amadurecimento de uma época dependa de nosso despertar, é mesmo uma pena que Benjamin não tenha terminado esse texto em particular, pois seu conteúdo teria sido muito útil para grandes dorminhocos como eu. "O que é apresentado a seguir", ele anunciava então, "é um ensaio sobre a técnica do despertar". (BENJAMIN, 2007, p. 433) Seja porque gosto de História - e acordando cedo eu teria mais tempo para ficar na biblioteca —, seja porque definitivamente desaprovo esse processo diário 
de autopunição, decidi fazer algo a respeito. Decidi, em uma palavra, tentar minha própria "técnica do despertar." Ou, no pior dos casos, tentar estabelecer a impossibilidade definitiva da coisa. É assim que demonstrações funcionam em geral.

O sono louco (ou Le Sommeil fou, com um acento surrealista francês) é o título de um projeto exibido recentemente na forma de instalação na galeria Casamata, no Rio de Janeiro. Suas origens remontam, entretanto, a meus anos de estudante em Paris, os últimos dos quais passados sob uma dessas construções que tanto fascinaram Benjamin, a prestigiosa galerie Vivienne, onde se havia instalado recentemente o Institut National d'Histoire de I'Art (INHA). Combinando métodos de pesquisa acadêmica com prática artística, o projeto investiga meus próprios problemas de sono, por meio de um teste caseiro. O objetivo desse experimento era medir, da forma mais precisa possível, os intervalos de tempo entre a hora estipulada do alarme e a hora real de meu despertar durante um período de um mês. Era então a minha hipótese não se tratar de uma questão de quantas horas eu havia dormido, nem mesmo da "qualidade" de meu repouso noturno. O problema estava claramente ligado ao ato de despertar em si mesmo, a uma dificuldade anormal na passagem entre o sono e a vigília, isto é, algo da ordem de um transtorno psíquico transitivo.

A primeira dificuldade para realizar o experimento era de método: como reunir os tão necessários dados que comprovassem a existência de meu problema? É bastante fácil saber a que horas alguém deveria ter acordado - trata-se da hora estipulada para o toque do alarme, representada na maioria dos despertadores mecânicos por uma agulha vermelha. Essa hora deverá ser chamada daqui em diante de Parâmetro X (PX.). Mas outra coisa é saber ao certo quando alguém realmente acordou - e isso dispensando a parafernália médica encontrada nos laboratórios modernos. Esse momento evanescente quando, ainda segundo Benjamin, "nós somos jogados para fora do reino do sono" é de fato um tanto misterioso. Chamemos então esse hipotético momento limiar de Parâmetro Y (Py.). Logo se tornou evidente que métodos de registro "artesanais", como tomar notas, mesmo de forma estenográfica, não dariam conta da tarefa. Como assinalou o escritor surrealista André Breton em 1922 em Entrée des mediums, ao relatar sua dificuldade em anotar seus sonhos, a memória é uma faculdade "profundamente deficiente e, de uma maneira geral, sujeita a caução". (BRETON, 1969, p. 120) Ademais, se meu problema era a passagem do sonho para a vigília, eu não podia contar com 
a minha consciência, sob a acusação de petição de princípio (petitio principii). Isso tinha de ser feito, em uma palavra, por uma máquina; uma que pudesse não apenas registrar minhas atividades noturnas, mas também reportá-las a mim mais tarde. Essa máquina é um relógio, é claro. Mas de que tipo? Após uma longa incursão na história dos relógios, esbarrei no único que me parecia capaz de parar o tempo, capturando um instante preciso com um golpe de mão, uma espécie de cronômetro reverso.

\section{2.}

O que veio a ser chamado de "relógio de ponto de vigia noturno", ou simplesmente "relógio de vigia", foi inventado já no século XVIII; mas o auge de seu uso se deu entre 1850 e 1950. Como consequência da emergência do capitalismo moderno e da revolução industrial, um grande número de fábricas e galpões começou a surgir, primeiro nos grandes centros e mais tarde nos subúrbios da Europa e dos Estados Unidos. Em uma época em que equipamentos de segurança como câmeras de vigilância ainda não existiam, a profissão do vigia noturno tinha uma importância vital, e um relógio que pudesse indicar a hora na qual o vigia contratado fazia suas rondas foi uma invenção muito bem recebida pelos empregadores.

Uma sequência do clássico filme de Fritz Lang M - O vampiro de Düsseldorf, de 1931, descreve de forma sucinta o funcionamento desse mecanismo revolucionário. Primeiro, vemos um grupo de bandidos invadir um galpão. Eles estão à procura de $\mathrm{M}$, o procurado pedófilo, o qual está indiretamente comprometendo o crime organizado em Düsseldorf devido à intensa busca e aos cercos da polícia. Depois de render a segurança local, os bandidos se dão conta de que eles também terão de jogar o jogo do relógio para manter a polícia longe dali, pois é possível deter um homem, mas não um relógio. Assim, toda a sequência se desvia subitamente do objetivo do bandidos e passa a concentrar-se em sua preocupação em bater o ponto na hora certa: "Preste atenção", explica o chefe, "este é um novo tipo de relógio de ponto. E aqui estão as plantas do prédio. Se os dispositivos não forem acionados na hora certa, eles disparam automaticamente na delegacia mais próxima. Entendeu?" O que é então apresentado ao público dos anos 1930 como uma peça de tecnologia de ponta é uma versão alternativa deste engenhoso aparato gravador de tempo. Mais comum à época era uma versão portátil do mesmo, porém ainda bastante pesada, carregada sobre o ombro pelo vigia noturno como 


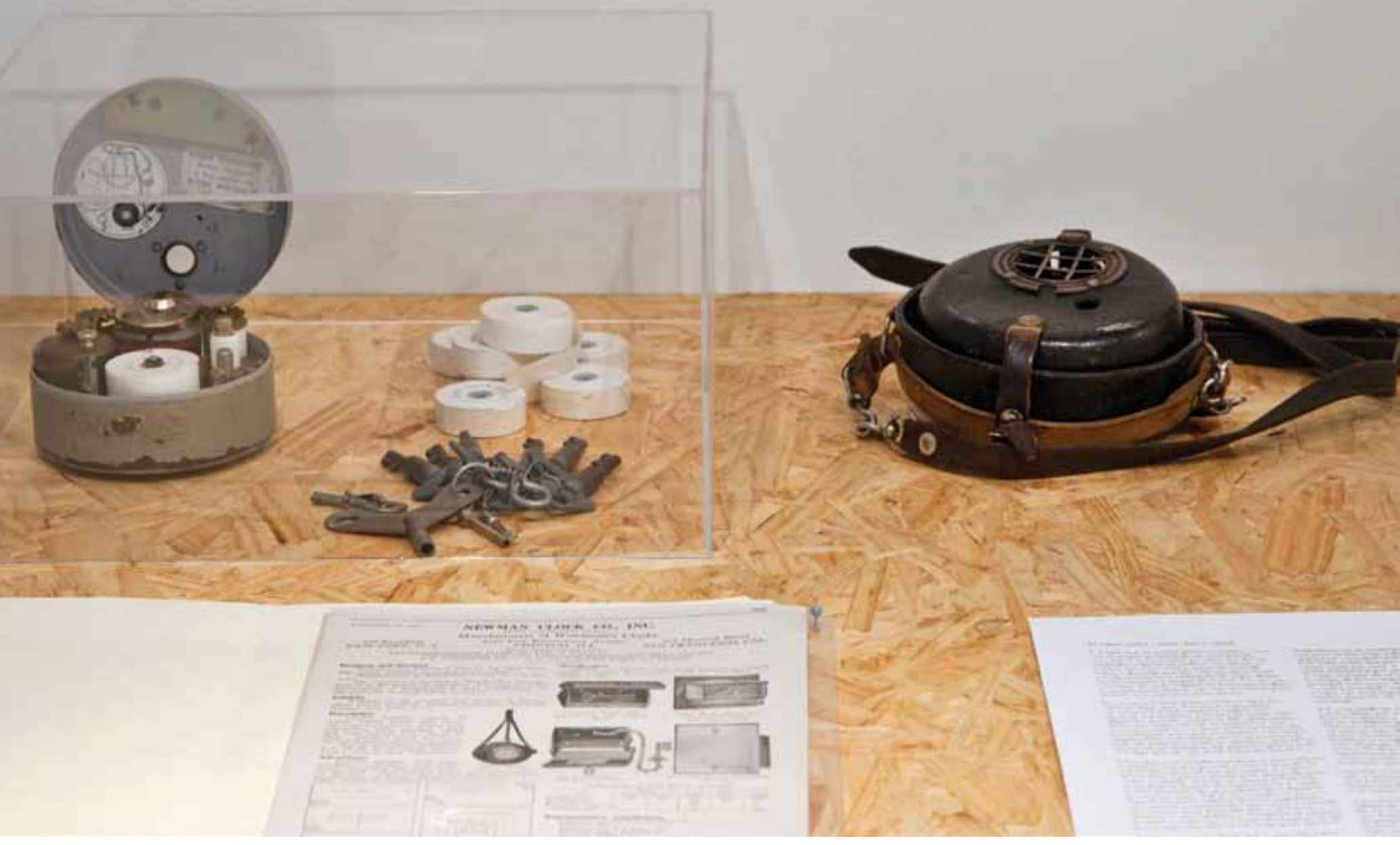

\section{Daniel Jablonski}

O sono louco - quem vigia o vigia?, relógio de ponto de vigia noturno, 2014.

(Fonte: Acervo do artista) 
um cantil e movida por um mecanismo à corda. Ele registrava precisamente a posição do vigia no tempo e no espaço durante toda a noite. Em cada um dos lugares pelos quais ele tinha de passar em sua ronda havia uma chave presa à parede em uma caixa de ferro. De tanto em tanto tempo, ele devia inserir uma dessas chaves e acionar o mecanismo, imprimindo assim um comprovante com a hora e o número da chave em uma pequena bobina de papel em seu interior - um registro detalhado, permanente e verificável da patrulha de cada noite.

Mas da mesma forma que os bandidos passam a ser preocupar mais em bater o ponto do que procurar por M, a preocupação central dos patrões se havia desviado de vigiar sua propriedade para vigiar a pessoa designada para tal tarefa. É o que se percebe facilmente hoje ao ler um dos anúncios de venda do relógio de ponto: "Fornece verificação exata sobre o vigia; ineficiência detectada imediatamente; adulteração impossível sem detecção. Traz o maior desconto em taxas de seguro para este tipo de dispositivo. Custo inicial baixo; manutenção esparsa". Esta era a verdadeira questão do neurótico mundo do trabalho do século XIX, e não precaver-se contra eventuais ladrões: se o capitalista precisa dormir à noite, como ele pode ter certeza de que seu empregado está de fato vigiando sua fábrica, isto é, de que ele não está sendo enganado pagando alguém para dormir também? É o que parece apontar, igualmente, o historiador inglês E. P. Thompson em sua análise da transição do modelo de trabalho do camponês e do artesão, orientado para a execução de tarefas específicas, para o mais complexo sistema de trabalho da sociedade industrial: "Aqueles que são empregados", diz ele, "têm a experiência de uma distinção entre o tempo de seu empregador e 'seu' próprio tempo. E o empregador tem de usar o tempo de seu trabalho e garantir que não seja desperdiçado: não são as tarefas, mas o valor do tempo quando reduzido a dinheiro que é dominante. Tempo é agora uma moeda: ele não passa, mas se gasta". (THOMPSON, 1967, p. 61) Portanto, tudo se resume a uma só questão: quem vigia o vigia? E a resposta, convenientemente, é esta aqui: o relógio.

Não é uma coincidência que a chave-mestra que garante toda a estrutura do trabalho no século XIX seja uma máquina. Sua introdução nas fábricas não havia transformado profundamente apenas a relação do capitalista com sua propriedade, mas também a relação de homens comuns com seu produto: o produtor é alienado de suas capacidades produtivas, nos diz a teoria marxista. Ele já não é um produtor, mas, de certa forma, se torna uma espécie de vigia diurno, designado apenas para manter toda a maquinaria funcionando de maneira adequada. Afinal, 
máquinas funcionam sozinhas ou, como se diz, automaticamente; no entanto, como nos lembra outro famoso invento do século XIX — o aparelho fotográfico - , de vez em quando elas necessitam também de um impulso orgânico para funcionar. E, claro, o homem se torna seu provedor, mas agora ele é chamado de "empregado". Suas tão celebradas faculdades mentais estão agora reduzidas a pressionar o botão, virar a chave e seguir as instruções. E não é de se espantar que já tenham sido organizadas em fábricas e usinas revoltas contra o relógio, esse mecanismo de alienação: uma significativa perda de consciência está aí, de fato, em jogo. Desse ponto de vista, um relógio de ponto não passaria de um mecanismo suplementar de alienação - por meio de dominação física - capaz de provar que seu portador esteve acordado durante a noite. Ele representaria assim, aos olhos do empregador, uma espécie de registro fotográfico da atividade noturna de seu empregado. Ou, numa corruptela do famoso "ça a été" de Barthes, "il a été", il a été là. Ele esteve aí. A cada vez que a chave, acorrentada à parede, é inserida no mecanismo, o relógio de ponto produz uma evidência irrefutável do estado de vigília do vigia: "eu estou acordado, eu estou acordado", e assim por diante — o que será lido na manhã seguinte pelo empregador como: "ele esteve acordado, ele esteve acordado", e assim por diante. As inscrições na bobina de papel, contendo dia, hora e posição do empregado durante suas rondas noturnas, poderiam ser vistas aqui, como índices ou rastros de uma consciência. Fotografias instantâneas tomadas no escuro.

Pensei então que, me submetendo a esse dispositivo, poderia observar meu próprio sono e manter um registro de minha atividade noturna, desdobrando-me assim nas posições do empregado e do empregador. Ou, ao menos, estabelecer o intervalo real entre os parâmetros $X$ e Y de forma estritamente mecânica. E foi o que fiz no mês de agosto de 2013, ao dormir no período de um mês amarrado a um desconfortável relógio de ponto de vigia noturno e virar a chave no mecanismos a cada vez que sentisse estar acordando. A última vez que o fizesse pela manhã, deveria ser então a definitiva. Com a exceção de que a chave, no meu caso, já estaria inserida no relógio durante a noite - eliminando o parâmetro espacial original e, com ele, a analogia com a figura do sonâmbulo — , o funcionamento me parecia ser exatamente o mesmo: um impulso orgânico, produzido por uma consciência reduzida, dispara o dispositivo mecânico.

Ora, não estaria eu manipulando os resultados com a expectativa de ter de virar a chave pela manhã? Não mais do que alguém que vai a um instituto do sono, é conectado a todo tipo de 
Segunda

Terea

Onuta

$$
x: 10430
$$

$y: 11$ Hs

$$
\Rightarrow \text { ofH21 }
$$

$02 / 09$

$$
\begin{aligned}
& x: 10 \mathrm{H} \\
& y: 10 \mathrm{HO4}
\end{aligned}
$$

$$
\begin{aligned}
& x: 11 \\
& y: 11 H 58 \\
& \Rightarrow 00 H S 8
\end{aligned}
$$

$03 / 09$

$$
\begin{aligned}
& x=10 H \\
& y=11+144 \\
& \Rightarrow 01 H 44
\end{aligned}
$$

$$
04 / 09
$$

$$
\begin{array}{r}
x: 10 H 30 \\
y: 11 H 13 \\
\text { and }
\end{array}
$$

Daniel Jablonsk

O sono louco - quem vigia o vigia?, inscrições nas bobinas de papel, 2014.

(Fonte: Acervo do artista) 
fios e eletrodos e, ainda assim, Ihe é dito para "dormir normalmente". Em um experimento no qual tanto o sono quanto o sonho estão sendo monitorados, estados psicológicos importam: eles não podem ser excluídos; ao contrário, devem ser interpretados. E os resultados mostraram que frequentemente, e apesar de meu problema de sono pela manhã, eu havia acordado diversas vezes durante a noite. Em uma ocasião até cinco vezes, mas eu não podia lembrar de nada. E este era também um ponto importante do problema: enquanto tenho a impressão de sonhar muito, nunca lembro de nada. Não tenho, até o dia presente, mais que dois ou três sonhos que pudesse contar a meu psicanalista... Se esse apagamento sistemático de todo o "conteúdo onírico" de meus sonhos era também parte da questão, agora eu ao menos tinha números. Eu havia produzido a evidência de que algo estava errado. Mas o quê? Os resultados da experiência pareciam apontar para a existência de um distúrbio psíquico ainda desconhecido, consistindo em uma clara resistência ao despertar, isto é, um problema de transição entre o sono e a vigília, pois o tempo médio de uma hora e vinte minutos não é, por nenhum critério conhecido, um atraso aceitável para o despertar. Decidi, assim, fazer o que faço em geral: pesquisa. E resolvi começar por uma doutrina perfeitamente contemporânea dessa época das máquinas e da alienação no trabalho: a então nova "ciência dos sonhos" de Sigmund Freud.

\section{3.}

Não é surpreendente que o pai da psicanálise tenha recorrido ao aparelho fotográfico como uma "analogia tosca, porém adequada" (FREUD, 2010, p. 199) para esclarecer como a psique realmente funciona. Por volta da década de 1910, a fotografia já era uma prática familiar a todos os senhores de boa educação da Europa. Como se lê no ensaio Algumas observações sobre o conceito de inconsciente na psicanálise, de 1912: "O primeiro estágio da fotografia é o negativo; toda imagem fotográfica tem de passar pelo 'processo negativo', e alguns desses negativos, que superaram bem a prova, são admitidos no 'processo positivo', que conclui com a imagem". (FREUD, 2010, p. 199-200) A analogia aponta ainda para o fato de que, ainda que intimamente relacionados, assim como a luz e as lentes, os processos inconscientes (Ics.) e pré-conscientes (Pcs.) não são idênticos. Nem mesmo em prioridade, pois todo processo psíquico, diz ele, tem sua fonte no inconsciente e pode depois mover-se - ou não - para 
regiões mais conscientes, dependendo de sua natureza e da intensidade da "censura" exercida pelo pré-consciente. Mas a analogia de Freud tem de passar por mais um espelho para ser compreendida, uma vez que a inversão da fonte luminosa, da percepção para o inconsciente, tem implicações fortes. Enquanto a imagem fotográfica convencional depende da luz do dia — sobretudo no século XIX —, o momento privilegiado para que tais imagens oníricas se revelem é durante a noite, no escuro, quando esse "processo de exame" é menos rígido. Esta é a famosa tese de Freud: com a necessidade da consciência de repousar à noite, vem também um relaxamento de seus poderes de censura, de forma que o desejo, ainda que travestido, por fim encontra uma maneira de se expressar. Em nossos sonhos, ele escreve, "um pedaço do inconsciente emergiu na consciência, o que normalmente não seria possível." (FREUD, 2010, p. 200) A imagem onírica invertida serviria, então, aos praticantes dessa jovem ciência como índices de nossa atividade inconsciente (ou nas palavras de Freud: "provas ou signos").

Contudo, seria sem dúvida um erro diminuir a importância dos sonhos para o "sistema secundário", o pré-consciente. Sonhos podem muito bem representar a realização de algum desejo reprimido da infância, mas também servem a outro desejo específico e incontornável: o desejo de dormir. E este, como percebe-se facilmente ao ler o famoso capítulo 7 da Interpretação dos sonhos, é um desejo atípico. A começar porque ele tem sua origem no sistema pré-consciente (Pcs.), e não no inconsciente (Ics.). Ao contrário de todos os outros desejos, ele não possui um conteúdo específico, apenas uma forma, de modo que não importa realmente qual desejo esteja em questão em determinada noite, o desejo de dormir nos acompanhará todas as noites. Esta é a razão por que os sonhos são, para Freud, uma espécie de "formação de compromissos" (FREUD, 1987, p. 525), servindo a ambos os sistemas: ao darem ao inconsciente a ilusão de realizar um desejo, os sonhos retomam o controle sobre o fluxo de energia noturna, garantindo assim a realização do desejo de dormir. Ou, como ele diz:

O sonho tomou para si a tarefa de recolocar sob o controle do pré-consciente a excitação do Ics. que ficou livre; ao fazê-lo, ele descarrega a excitação do lcs., serve-lhe de válvula de escape e, ao mesmo tempo, preserva o sono do pré-consciente, em troca de um pequeno dispêndio de energia de atividade de vigília. (FREUD, 1987, p. 526-7)

De um ponto de vista estritamente energético, é mais econômico deixar as moções inconscientes fluírem durante a noite do que tentar manter a função de censura ativa. Em vez de 
apenas bloquear o fluxo dos desejos, como durante o dia, o pré-consciente age aqui, em um modo de atenção reduzida, como um aparato de regulação. É bastante significativo que Freud utilize aqui a expressão "válvula de escape", a qual pode ser chamada também de válvula de pressão. Trata-se de um termo de mecânica fazendo eco a outra interessante "analogia física" de que se serve o autor: a da represa. Essa estrutura faz mais do que somente barrar o fluxo da água; sua função é regulá-lo. Freud usa a palavra alemã Abströmen para descrever a natureza da energia do inconsciente do sistema primário, algo como uma "livre descarga de quantidades de excitação", tal qual lemos na nota de pé de página do livro, com a conotação de uma "saída torrencial." (FREUD, 1987, p. 543) O sistema secundário, ele acrescenta, "represa" então esse fluxo. Temos aqui, portanto, dois sistemas distintos trabalhando de forma complementar. É bastante revelador encontrar ainda, próximo à ideia da máquina, o campo lexical da água, pois a água sempre foi de certa forma uma metáfora privilegiada para a passagem do tempo. E não é uma coincidência que algum dia tenha ocorrido a alguém utilizar o princípio de uma das primeiras máquinas construídas — o moinho de água — para medir o tempo. O primeiro relógio mecânico de que se tem notícia, movido a água, foi concebido no século XI nas bases de um moinho pelo polímata chinês Su Sung. Foi só muito mais tarde, no seio de um mundo ocidental cada vez mais abstrato, que outro processo natural periódico substituiu a água: a oscilação do pêndulo. Esse movimento, descoberto por Galileu Galilei, capaz de ser infinitamente repetido e mensurado, foi utilizado então no primeiro relógio de fato mecânico em 1656, por Christian Huyghens.

Assim como para os dois sistemas descritos por Freud anteriormente, cabe dizer que a natureza da água e a do moinho são sem dúvida distintas - contudo elas se conectam de alguma maneira, e a energia é transferida de um a outro. Da mesma forma, entre o suposto tempo "real" e o tempo mecânico, há com certeza um abismo ontológico, mas sua relação parece ser também regulada. Esta é a mesma estranha regulação que conectaria então o tempo do sono com o tempo do sonho. Embora fique claro que não são o mesmo - e Freud rejeita claramente a teoria de Goblot segundo a qual os sonhos ocorreriam apenas em fases transitivas do sono - eles estão relacionados. A função dos sonhos, diz Freud, é manter o corpo em descanso por algumas horas. Eles são, desde sua dimensão atemporal, "os guardiões do sono"; este último, um fenômeno não só regulado por necessidades fisiológicas, como também subjugado pela divisão do tempo herdada do século XIX. 


\section{4.}

Mas os sonhos sempre "têm um efeito despertador" (FREUD, 1987, p. 523), acrescenta ele. Seja porque a energia corporal foi inteiramente restaurada ou porque algo deu errado nas moções inconscientes — como em sonhos de angústia, por exemplo —, o despertar é também uma função vital dos sonhos. Em um texto intitulado Sobre os sonhos, a analogia com o moinho é explicitada: "como a mãe, por exemplo, é acordada pelo choramingar de seu bebê, o moleiro pela paralisação de seu moinho, e a maioria das pessoas, ao ser suavemente chamada por seu próprio nome". (FREUD, 1987, p. 606) E Freud aponta aqui para um novo personagem: o moleiro, o indivíduo responsável pelo funcionamento do moinho. Seu trabalho é bastante similar ao do vigia noturno. E é também interessante notar que o mesmo efeito de alienação da máquina vem sempre trazer uma perversão às suas promessas liberadoras originais. Estas já podem ser encontradas de forma explícita em um fragmento do antigo epigramista grego Antípatro de Tessalônica, no qual se faz o primeiro elogio de uma máquina (85 a.C.) por sua utilidade na moagem dos grãos e na subsequente redução do trabalho humano:

Para de moer o grão, ó mulher que te esfalfas no moinho, dorme até tarde, mesmo que o canto do galo anuncie a alvorada, porque Deméter ordenou às ninfas que realizem por suas mãos o trabalho e, inclinando-se no cimo da roda, elas fazem girar as pás que movimentam a pesada pedra molar de Nysis. (GIMPEL, 2001, p. 20-21)

Isso, é claro, revelou-se uma grande ilusão: a redução do trabalho de um homem pela máquina sempre vem ao preço do emprego de outro homem — nesse caso, do moleiro. Isso também se aplica ao século XIX: os sonhos agradáveis do empregador dependem por completo da consciência (ainda que reduzida) de seu empregado, o vigia noturno. E este é também finalmente citado no texto de Freud: "Os sonhos agem", ele escreve em 1901, "como um vigia noturno consciencioso, que primeiro cumpre seu dever pela supressão das perturbações, para que os cidadãos não sejam despertados, mas depois continua a cumpri-lo, indo ele próprio acordar os cidadãos, quando as causas da perturbação lhe parecem graves e de um tipo que ele não pode enfrentar sozinho". (FREUD, 1987, p. 606)

Antes nos perguntamos: quem vigia o vigia? Poderíamos dar um passo atrás e perguntarmo-nos agora: o que exatamente esse vigia está vigiando? Com certeza não o que ele foi designado para vigiar, isto é, a propriedade privada do empregador. Ele vigia, antes, o sono 
tranquilo do seu empregador. Com o início da sociedade industrial, se modificam sensivelmente também as relações sociais entre segurança e sono. Se antes, o soberano era ainda visto como uma espécie de grande "vigia", responsável pela segurança até do mais pobre de seus súditos, é agora uma classe específica que exigirá do Estado proteção contra as demais: a burguesia. E essa segurança não diz respeito apenas à sua integridade física durante o dia, no comércio com os demais indivíduos, mas também à de seus bens materiais durante a noite, enquanto dormem. A posição do vigia noturno privado vem, desde essa época, sanar as insuficiências do Estado em seu papel de refrear a "ansiedade" do sujeito em relação à sua propriedade, para que este possa dormir. Ora, se o vigia noturno é de fato o guardião do sono do seu empregador, é ele o único encarregado por garantir a realização dos desejos reprimidos de infância deste último. Ou, pelo menos, de seu desejo de dormir. Em termos puramente freudianos, poderíamos dizer que esse empregador obsessivo e controlador durante o dia se torna uma criança durante a noite, acreditando plenamente no conteúdo dos seus sonhos. Ao fazer isso, conclui Freud, "nosso eu tende a se comportar como uma criança; dá crédito às imagens do sonho, como se quisesse dizer: 'sim, sim! Você tem toda a razão, mas deixe-me continuar dormindo!'" (FREUD, 1987, p. 606)

Segue aqui uma tentativa de interpretação do transtorno psíquico do qual eu acredito sofrer: Eu sou esse empregador, que é também uma criança à noite. E toda a questão é: meu "guardião" também parece estar adormecido e ninguém está vigiando meu sono. Um claro desejo de retorno à infância estaria aqui explícito, não porque todo sonho é a realização de um desejo infantil ou porque, numa palavra, todo sonhador é uma criança ("sim, sim!"); mas, em última instância, porque eu estaria ainda esperando que outra pessoa - digamos, meus pais - me acorde pela manhã. Como uma criança, eu me desligaria à noite de todas as minhas responsabilidades adultas, evacuando toda a "atenção" que me é tão característica... Porém, infelizmente, eu vivo sozinho e não há ninguém para me acordar... Nessa luta diária e dolorosa entre o sono e a vigília estaria em jogo então um processo de amadurecimento que já tomou um quarto de século para acontecer, indo do meu nascimento até aquele momento. Toda manhã, nessa fase transitiva, que me toma de poucos minutos a longas horas, eu teria de "crescer" de uma criança sonhadora a um adulto neurótico de 28 anos. Isso explicaria por que sempre detestei a escola: só porque era muito cedo pela manhã. E o mesmo poderia ser dito de meu amadurecimento acadêmico, que foi bastante tardio. Poderia ainda explicar, finalmente, 
meu péssimo humor pela manhã, como resultado da culpa por ter acordado sempre "tarde demais." Afinal, toda manhã o empregador pune essa criança que Ihe tomou o lugar durante a noite pela negligência de haver deixado sua propriedade privada sem vigilância.

\section{5.}

Na sequência de minha fala no congresso em que apresentei o projeto pela primeira vez, em outubro de 2013, pessoas de grupos distintos me perguntaram se já havia lido o último livro do filósofo norte-americano Jonathan Crary, intitulado 24/7 - Late Capitalism and the Ends of Sleep. Aproveito a publicação deste artigo para Ihes responder brevemente, ainda que com um ano de atraso. No volume em questão, me parece, Crary busca expandir a crítica marxista tradicional às novas ferramentas de alienação do século XXI. Após a ocupação de todos os territórios livres do planeta, o novo capitalismo global coloniza agora o tempo do homem, borrando em definitivo as fronteiras entre trabalho e ócio e transformando-o em fornecedor e consumidor de sua própria imagem, eternamente disponível nas novas mídias digitais. E ele sentencia: "Um mundo 24/7 iluminado e sem sombras é a última miragem capitalista da pós-história de um exorcismo da outreidade [otherness] que é o motor da mudança histórica". (CRARY, 2013, p. 9) Diante desse cenário, o sono - com sua interrupção diária do ritmo frenético da vida contemporânea - é alçado à categoria de forma de "resistência biopolítica". Só nos resta, diz ele, dormir profundamente e sonhar coletivamente com dias melhores. Esse raciocínio é revelador no que se distingue do que foi a tentativa de Walter Benjamin há quase um século: a saber, de "interpretar o século XIX como a consequência do sonho". Enquanto Crary, vítima de um sintoma de sua época - a insônia - , faz um elogio rasteiro do sono, Benjamin já nos brindava com uma tentativa de voltar ao marxismo após a psicanálise, e não a despeito dela. Tratava-se, para o filósofo alemão, de "transferir" as descobertas de Freud "do individual ao coletivo", procurando identificar um caráter expressivo nas partes viradas para o sonho que modelam uma época: não apenas em pessoas, em seus medos e desejos, mas também "nos primeiros produtos e edifícios industriais, nas primeiras máquinas [...], nos primeiros grandes armazéns, anúncios publicitários". (BENJAMIN, 2007, p. 435) Não é de se espantar, portanto, que Crary não veja na teoria analítica de Freud mais que um signo, entre outros, da neutralização da eficácia social dos sonhos ou, em suas palavras, de um 


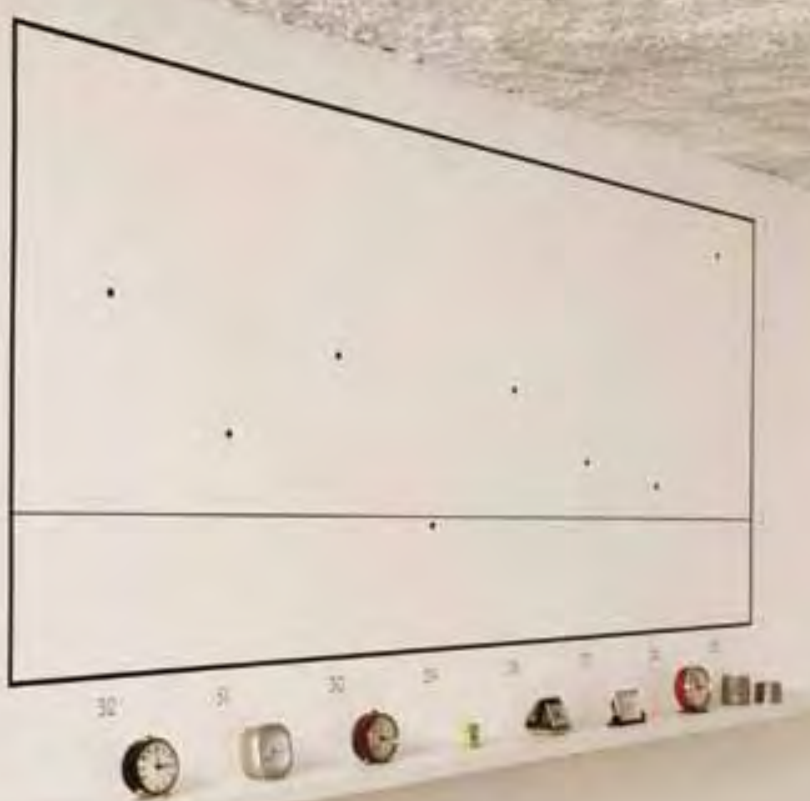

Daniel Jablonski

O sono louco - quem vigia o vigia?, vista geral da exposição, 2014.

(Fonte: Acervo do artista) 
"apagamento mais vasto da possibilidade de sua significação trans-histórica". (CRARY, 2013, p. 108) Ao atribuir sua origem à infância traumática do indivíduo, Freud teria tentado "domesticar o que estava fora de seu controle", levando a cabo assim o projeto pequeno-burguês de "privatização dos sonhos". (CRARY, 2013, p. 107)

A despeito da superficialidade gritante de sua crítica, a qual parece ignorar o aspecto radicalmente coletivo do inconsciente já vislumbrado por Benjamin, Crary acaba por levantar uma questão fundamental: a relação profunda entre o capitalismo industrial e a psicanálise na virada do século XIX para o XX. A analogia do sonho como vigia noturno não é fortuita em Freud, e o relógio de ponto é apenas um dos muitos dispositivos dessa época que apontam para a homologia fundamental entre as funções de "controle" nas duas esferas sobre as quais estas legislam: as relações de trabalho de um lado e a psique humana de outro. Mas há aqui uma escolha. Ou se toma a via marxista clássica, ainda que atualizada aos dilemas do século XXI, e se segue pregando a libertação do homem por meio do combate contra as mais diversas formas de alienação; ou se toma a via de um marxismo assombrado por fantasmas e desejos, sugerindo que a alienação pode ser um efeito estrutural e, portanto, condição mesma da liberdade a ser alcançada. Pois o inconsciente, se pensado como aquilo que separa o sujeito de si mesmo de entrada, parece funcionar ele próprio como uma máquina, descentrando o ser humano e a consciência de seu lugar de privilégio simbólico. E vai de si que este não pode ser "individual", uma vez que ao sujeito, ao burguês, ao patrão mesmo, cabe agora controlar os "fluxos de energia" que dele se desprendem sozinhos, automaticamente. Por isso, a partir de Freud - e sob risco de complicar todo o importante campo da luta de classes - todo capitalista é também um proletário de si mesmo, encarregado do controle de seus processos inconscientes. Desse ponto de vista, não seria suficiente dizer apenas, como Crary, que a psicanálise é um subproduto do sociedade burguesa. Haveria de se dizer, muito mais além, que as próprias relações de trabalho no capitalismo industrial já tinham algo de inconsciente; que, em uma palavra, todos os produtos, as indústrias, as máquinas e os armazéns que Benjamin buscava se apresentavam no espaço coletivo como uma espécie de arquitetura estrutural da psique humana. E, em primeiro lugar, o relógio. É o que parece sugerir um provocador Jacques Lacan, indo de um só golpe contra toda a tradição francesa do "tempo verdadeiro", de Bergson a Canguilhem, ao afirmar em 1955: "As máquinas são outra coisa. Isso vai muito mais longe, na direção daquilo que realmente somos, do que as próprias pessoas que as 
constroem suspeitam [...]. A máquina encarna a mais radical atividade simbólica no homem, e ela era necessária para que as questões se colocassem no nível em que as colocamos para nós". (LACAN, 1985, p. 98)

\section{Referências}

BENJAMIN, Walter. Passagens parisienses II (1927-1929). In Passagens. Belo Horizonte: Editora UFMG, 2007.

BENJAMIN, Walter. Rua de mão única (1928). Obras escolhidas II. São Paulo: Brasiliense, 1995.

BRETON, André. Entrée des médiums. In Les pas perdus. Paris: Gallimard, 1969.

CRARY, Jonathan. 24/7 - Late Capitalism and the Ends of Sleep. Londres, Nova York: Verso Books, 2013.

FREUD, Sigmund. Algumas observações sobre o conceito de inconsciente na psicanálise (1912). In Obras completas, Volume 10. São Paulo: Companhia das Letras, 2010.

FREUD, Sigmund. A interpretação dos sonhos (1900), seguido de Sobre os sonhos (1901), Volume 2. Rio de Janeiro: Imago, 1987. GIMPEL, Jean. A Revolução Industrial da Idade Média (1975). Mem Martins: Publicações Europa-América, 2001.

LACAN, Jacques. Seminário // (1955). Rio de Janeiro: Jorge Zahar, 1985.

THOMPSON, Edward Palmer. Time, Work-Discipline, and Industrial Capitalism. Past and Present, Oxford, n. 38, p. 56-97, dez. 1967. 